\title{
ASSESSING AFLATOXIN M1 LEVELS AMONG LACTATING MOTHERS' IN DAMATURU YOBE STATE, NIGERIA
}

Alegbe, S. D. ${ }^{1 *}$; Yakubu, S. E. ${ }^{1}$; Olonitola, S. $0 .{ }^{1}$; Mukhtar, M. D. ${ }^{2}$

${ }^{1}$ Department of Microbiology Ahmadu Bello University Zaria, Kaduna State.

${ }^{2}$ Department of Microbiology Bayero University

*Correspondence author: davidmails@gmail.com; 08069601527"

ABSTRACT

Aflatoxin M1 (AFM1) is a biomarker of aflatoxin B1 exposure in breast milk, a possible risk factor for infant early exposure to Aflatoxin. Aflatoxin B1 (AFB1) is a carcinogenic metabolite from Aspergillus fungus ingested from diet. One hundred (100) lactating mothers were sampled in General Sani Abacha Specialist Hospital Damaturu with infant's in-patient wards. Samples of breast milk and urine were collected aseptically and transported to the laboratory for analysis. Structured questionnaire was used to identify the possible food consumed within $72 \mathrm{hrs}$ to suggest possible source of aflatoxin exposure. Qualitative and quantitative analyses of breast milk samples were carried out by high performance liquid chromatography (HPLC). The occurrence of AFM1 showed $82 \%$ of the breast milk samples were positive to Aflatoxin M1. The occurrence of $93 \%$ of AFM1 excreted in their urine shows exposure to the toxin for a short time period. AFM1 excreted in urine of lactating mothers within $72 \mathrm{hrs}$ of acclaimed food consumption, showed $97.1 \%$ of mothers that took milk were exposed, meat: $100 \%$, corn meal: $93.4 \%$, also, date: 93\%, 'Brabiskol Biski': $30.6 \%$, imported rice : $77.7 \%$, native rice: $93.4 \%$ occurrence taken( $p<0.05$ ). Concentration of AFM1 among lactating mothers' breast milk in relation to socio-demographic factors expressed the highest

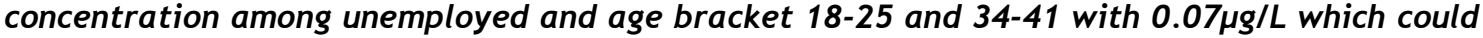
be that the employed mothers were more careful with quality of food they consumed while the unemployed mothers may concentrate on the quantity of food they took. In the case of excretion in urine, $0.05 \mu \mathrm{g} / \mathrm{L}$ AFM1 was detected among unemployed study participants with lower concentration among the age of 42 and above having $0.04 \mu \mathrm{g} / \mathrm{L}$. The concentrations of AFM1 in all the breast milk samples were higher than the acceptable tolerance level of 0.05 $\mu \mathrm{g} / \mathrm{L}$ as recommended by the Codex Alimentarius. This is a serious indication that lactating mothers ingest aflatoxin contaminated food which may be public health concern.

Keywords: Aflatoxin, Limit, Contamination, Biski, Chromatography

\section{INTRODUCTION}

Aflatoxins was discovered in 1960 immediately after an outbreak of a disease of turkeys of unknown etiology in England. The disease then was called Turkey " $X$ " disease and was eventually attributed to a toxic groundnut meal imported from Brazil (Blout, 1961 and Bunett et $a l, 2003)$. This encouraged an extensive effort to find the cause eventually elucidated that a species of mold, called Aspergillus flavus, was involved and the hepatotoxic products of this mold, found also as components in the toxic groundnut meal, were called aflatoxins (Richard 2008).

Mothers are exposed to many toxins that can reach their infants through breast milk. One of these toxins is aflatoxins, produced by the fungus, Aspergillus. Aspergillus colonizes grains, especially in tropical regions where there is high temperature and humidity. Aflatoxins are highly toxic, mutagenic, teratogenic, and carcinogenic. One of these aflatoxins is aflatoxin B1 that is excreted in breast milk as aflatoxin M1 (AFM1) (Ghiasian, 2012).Mycotoxins are toxic metabolites produced by special fungal strains. They are one of the most potent toxic substances produced by the fungi Aspergillus flavus and $A$. parasiticus. (Ghiasian, 2012). Adejumo et al. (2013) reported that the degree of contamination by $\mathrm{AFB}_{1}$ and $\mathrm{AFM}_{1}$ of lactating mothers was low in Ogun State.

Aflatoxin can contaminate many foodstuffs at various stages. Poor harvesting practices, improper drying, handling, packaging, storage, and transport conditions contribute to fungal growth and increase the risk of mycotoxin production. Aflatoxins have a high presence in tropical and subtropical regions where humidity and temperature conditions are optimal for toxin production Kamker et al. (2008). Until now, nearly 18 different types of Aflatoxins have been identified; aflatoxin B1 (AFB1) is considered as one of the most toxic (Bhet et al., 2010). 
Mammals that ingest AFB1-contaminated diets eliminate into milk amounts of the principal 4hydroxylated metabolite known as 'milk toxin' or aflatoxin M1 (AFM1) (Masri et al., 1974). Therefore aflatoxin $M 1$ is a biomarker for the exposure of aflatoxin B1 (AFB1) among lactation women.

\section{MATERIALS AND METHODS \\ Study Area}

The study area comprises General Sani Abacha Specialist hospital located in Damaturu, the capital city of Yobe, State, Nigeria.

Damaturu is a local Government Area (LGA) in Yobe State, Nigeria. It's headquarter is in the town of Damaturu, which is also State capital. The postal code of the area is 620 . The Local Government Area has an area of $2,366 \mathrm{~km}^{2}$ and a population of 88,014 as per the 2006 census. The town of Damaturu is on the A3 highway and has an estimated 2010 population of 44,268. The emirate is called Damaturu Emirate one time part of the Ngazaragamo emirate based in Gaidam. The northeasterly line of equal latitude and longitude passes through the area including $12^{\circ} 00^{\prime} 00^{\prime \prime} \mathrm{N} 12^{\circ} 00^{\prime} 00^{\prime \prime} \mathrm{E}$ in the north (Post Offices- with map of LGA,2012).

\section{Ethical Clearance and Consent}

Ethical clearance was obtained from the Ethical and Scientific Research Committee of the Ministry of Health, Damaturu. A consent form was given to obtain permission from lactating mothers. Only those who gave consent were recruited in the study.

\section{Sample Size}

In assessing the percentage occurrence of aflatoxin $M 1$, one hundred samples of breast milk were selected from mothers that had their children hospitalized.

Breast Milk Collection:

Breast milk samples were collected $(10 \mathrm{ml})$ by hand expression into glass tubes; the milk samples were stored at $-20^{\circ} \mathrm{C}$. Samples were thawed gradually to $4^{\circ} \mathrm{C}$ and then centrifuged at $10^{\circ} \mathrm{C}$ at $15 \mathrm{rpm}$. Aflatoxins are water-soluble; hence, the upper creamy layer was discarded and the lower phase was used for the quantitative test (Adejumo, 2013).

Urine Sample Collection

Lactating mothers' urine samples and their infants' urine samples were collected separately in plastic urine containers and transferred immediately to the laboratory and stored at $-20{ }^{\circ} \mathrm{C}$ (Manson et al., 2015).

Laboratory Analysis of Samples:

AF M1 was extracted from the breast milk according to the International Standard Organization (1998) with slight modifications. Adejumo (2013) was adopted. Forty (40) ml distilled water was added to $10 \mathrm{ml}$ of breast milk in $\mathrm{a} 100 \mathrm{ml}$ beaker followed by the addition of $0.25 \mathrm{~g} \mathrm{NaCl}$ and the solution properly mixed. The mixture was then centrifuged at $4000 \mathrm{rpm}$ for $10 \mathrm{~min}$. After separation, the skim portion (bottom layer) was filtered through a glass microfiber filter and $8 \mathrm{ml}$ of the filtrate passed through an immunoaffinity column fitted on a solid phase manifold at a flow rate of 12drop/s. Eight (8)millilitres of methanol: water $(10: 90)$ was used to wash the column and the bound aflatoxin $\mathrm{M} 1$ eluted with $3 \mathrm{ml}$ of methanol into an amber vial at the rate of 1-2 drop/s. The eluate was dried in acentrifugal evaporator vacuum centrifuge reconstituted in $200 \mu \mathrm{l}$ of methanol and $50 \mu \mathrm{l}$ portion injected into HPLC for analysis.

A calibration curve was constructed for AF M1 using different levels of toxin concentrations with an average of 10 consecutive automated injections of standard solutions of AF M1 purchased from SUPELCO solutions within ${ }^{T M}$ USA. Involving series of dilutions (Adejumo, 2013).

\section{Data Analysis}

The Statistical Package for Social Science program (SPSS, Chicago, Illinois, USA) version 21 was used for analysis of data. Data was summarized as mean, standard deviation, for the analysis of the difference in quantitative data between the two groups. The $X^{2}$-test was used for the analysis of qualitative data. $P$ value was considered significant if it was less than 0.05. Simple linear correlation (Pearson's correlation for quantitative data Tomerak, 2011).

\section{Analytical performance}

The limit of detection (LOD) for AFM1 was estimated at $0.01 \mu \mathrm{g} / \mathrm{mL}$ and the limit of quantification (LOQ) was $0.05 \mu \mathrm{g} / \mathrm{mL}$. The linearity of the curve was $0.01-0.05 \mu \mathrm{g} / \mathrm{mL}$. The calibration curve for AFM1 had a linear equation of $y=4147 . x-230.3$; Figure 1 gives the calibration curve with a correlation coefficient $\mathrm{R}^{2}=0.993$ and retention time of $10.0 \mathrm{~min}$.

\section{RESULTS}

From the result obtained the occurrence rate and concentration of Aflatoxin M1 in lactating mothers' breast milk and urine are summarized as follows:

Table1 shows the occurrence of AFM1 in 100 lactating mothers and their infants. Higher occurrence of $93.3 \%$ of AFM1 was recorded in urine samples of lactating mothers when compared with $82 \%$ in their breast milk. There was no statistically significant association in AFM1 occurrence between breast milk and 
urine of lactating mothers $\left(O R=0.987 ; x^{2}=1.765 ; p=0.457\right)$.

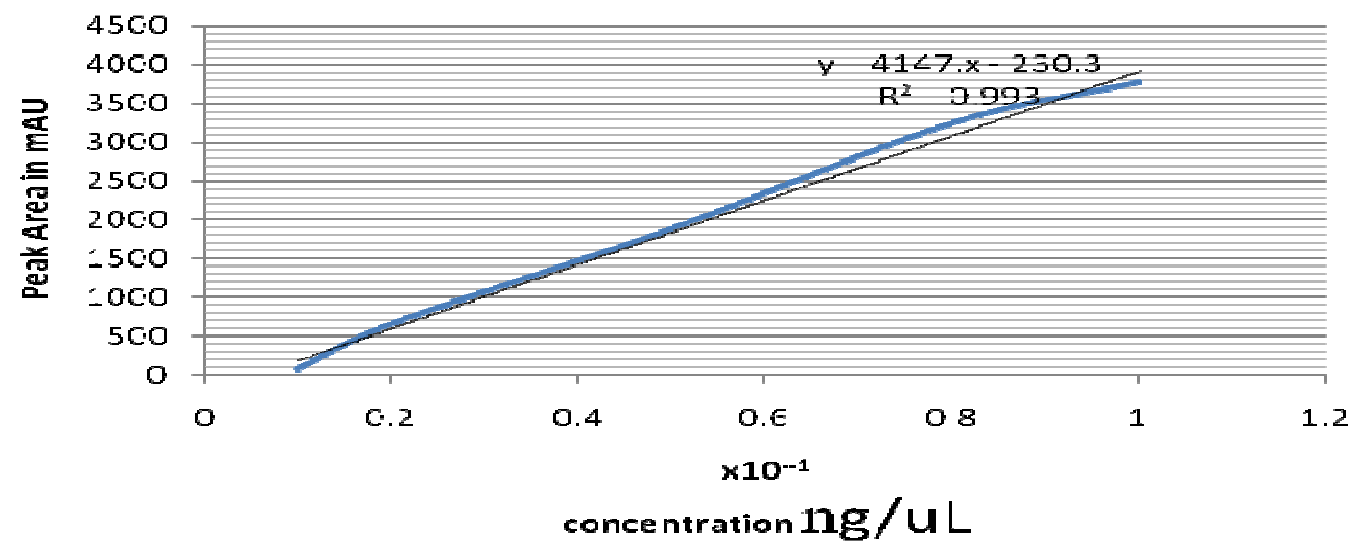

Key: $\mathrm{mAU}=$ milli adsorbent unit

Figure 1: Calibration curve for AFM1

Percentage occurrence of AFM1 in breast milk and urine samples of lactating mother in relation to selected socio-demographic factors can be observed in table 2. The levels of contamination of breast milk samples from 100 mothers, shows occupation as factor, unemployed mothers recorded higher occurrence of $83.9 \%$. There was statistically significant association between the occurrence of AFM1 among employed and unemployed participants. $\left(\mathrm{OR}=2.312, \mathrm{x}^{2}=12.687 ; \mathrm{p}=0.045\right)$. Age brackets $18-25$ showed higher occurrences of $83.6 \%$, and there was significant association between the ages of participants and the occurrence of AFM1 $\left(x^{2}=8.121 ; p=0.034\right)$. The occurrence of AFM1 was found to be highest among those with informal education with $97.4 \%$ and there was statistically significant association between their educational status and aflatoxin occurrence $\left(x^{2}=7.065 ; p=0.05\right)$.

The percentage occurrence of AFM1 in the urine of lactating mothers in relation to the Socio-demographic factors (table 2). AFM1 occurrence was higher among unemployed mothers with $100 \%$ occurrence and significant statistical association (OR=2.564, $\mathrm{x}^{2}=20.451$; $\mathrm{p}=0.001$ ). Age had significant association with AFM1 occurrence. Mothers between 42 and above had $100 \%$ positively $\left(x^{2}=5.671 ; p=0.047\right)$. Education status also influence AFM1 occurrence. Mothers with informal education had $100 \%$ exposure and there was significant association between educational status and exposure. $\left(x^{2}=8.756 ; p=0.048\right)$.
Table 3 shows the occurrence of AFM1 in urine samples of lactating mothers with respect to the food they consumed within $72 \mathrm{hrs}$ prior to sample collection. Around $97.1 \%$ of the mothers consumed milk (OR $=2.141 \mathrm{x}^{2}=8.247 ; \mathrm{p}=0.046$ ); $100 \%$ of the mothers consumed Meat, corn meal was consumed by the mother $93.4 \%$ (OR = $\left.0.654, x^{2}=10.23 ; p=0.014\right)$; Date was consumed by $93.3 \%\left(O R=2.789 x^{2}=8.911 ; p=0.043\right)$; while 'brabisko/biski' (local food) $30.6 \%$ (OR $=1.154$ $\left.x^{2}=11.654 ; p=0.048\right)$. From the results $97.4 \%$ of the mothers did not consume imported rice (OR $\left.=1.010 x^{2}=7.521 ; p=0.063\right)$; but $93.4 \%$ of them consumed native rice $\left(O R=2.500 x^{2}=9.112\right.$; $\mathrm{p}=0.050$ ).

Some of the socio-demographic factors associated with aflatoxin $M 1$ exposure in tables 2 and 4 are occupation, Age, and educational level showing statistical significance with $p \leq 0.05$. The urine sample shows a very strong statistical association in respect to occupational status $(p=0.001)$. However ages 34-41 had the least percentage exposure in their breast milk (60\%). But 18-25 and 34-41 had more aflatoxin $M 1$ both in breast milk and urine samples $(0.07 \mathrm{ug} / \mathrm{L})$. The category of food lactating mothers consume in table 4 within $72 \mathrm{hrs}$ shows that those that consume meat, milk, corn meal, date and native rice had the highest percentage exposure to aflatoxin: $100 \%$, $97.1 \%, 93.4 \%, 93.3 \%$ and $93.4 \%$ respectively. However those that consume local food had lower percentage of $30.6 \%$.

Table 1: Occurrences of AFM1 Among Lactating Mothers In Damaturu Yobe, Nigeria

\begin{tabular}{llllll}
\hline $\begin{array}{l}\text { Samples } \\
\text { Mothers }\end{array}$ & No examined & $\begin{array}{l}\text { No. positive } \\
\mathbf{( \% )}\end{array}$ & Odds ratio & $\begin{array}{l}\text { Chi } \\
\text { square }\end{array}$ & p-value \\
Breast milk & 100 & $\mathbf{8 2 ( 8 2 . 0 )}$ & $0.987(0.678-1.654)$ & 1.765 & 0.457 \\
Urine & 100 & $93(93.0)$ & & & \\
\hline
\end{tabular}


Special Conference Edition, November, 2017

Table 2: Percentage Occurrence Of AFM1 In Breast Milk And Urine Samples Of Lactating Mothers In

\begin{tabular}{|c|c|c|c|c|c|}
\hline Samples /Category & $\begin{array}{l}\text { No } \\
\text { examined } \\
\mathrm{N}=100\end{array}$ & $\begin{array}{l}\text { No. } \\
\text { positive }\end{array}$ & (\%) & Chi square & p-value \\
\hline \multicolumn{6}{|l|}{ BREAST MILK } \\
\hline \multicolumn{6}{|l|}{ Occupation } \\
\hline Employed & 13 & 9 & 69.2 & 12.687 & 0.045 \\
\hline \multirow{2}{*}{\multicolumn{6}{|c|}{ Age (yrs) }} \\
\hline & & & & & \\
\hline $18-25$ & 55 & 46 & 83.6 & & \\
\hline $26-33$ & 39 & 32 & 82.1 & 8.121 & 0.034 \\
\hline $34-41$ & 5 & 3 & 60.0 & & \\
\hline 42 above & 1 & 1 & 100 & & \\
\hline \multicolumn{6}{|l|}{ Educational level } \\
\hline Informal & 39 & 38 & 97.4 & & \\
\hline Islamic & 43 & 30 & 69.7 & 7.065 & 0.05 \\
\hline Primary & 12 & 9 & 75.0 & & \\
\hline Secondary & 6 & 5 & 83.3 & & \\
\hline \multicolumn{6}{|l|}{ URINE } \\
\hline \multicolumn{6}{|l|}{ Occupation } \\
\hline Employed & 13 & 6 & 46.1 & 20.451 & 0.001 \\
\hline Unemployed & 87 & 87 & 100.0 & & \\
\hline \multicolumn{6}{|l|}{ Age (yrs) } \\
\hline $18-25$ & 55 & 51 & 92.7 & & \\
\hline $26-33$ & 39 & 36 & 92.3 & 5.671 & 0.047 \\
\hline $34-41$ & 5 & 5 & 100.0 & & \\
\hline 42 above & 1 & 1 & 100.0 & & \\
\hline \multicolumn{6}{|l|}{ Educational level } \\
\hline Informal & 39 & 39 & 100.0 & & \\
\hline Islamic & 43 & 37 & 86.0 & 8.756 & 0.048 \\
\hline Primary & 12 & 12 & 100.0 & & \\
\hline Secondary & 6 & 5 & 83.3 & & \\
\hline
\end{tabular}

Table 3: Occurrence Of AFM1 In Urine Samples Of Mothers With The Types Of Food The Consumed Within 72 Hrs Prior To Sample Collection.

\begin{tabular}{|c|c|c|c|c|c|}
\hline $\begin{array}{l}\text { Consumed } \\
\text { foods in } 72 \\
\text { hrs }\end{array}$ & $\begin{array}{l}\text { No examined } \\
\mathrm{N}=100\end{array}$ & $\begin{array}{l}\text { No. positive } \\
\text { (\%) }\end{array}$ & Odds ratio & Chi square & p-value \\
\hline \multicolumn{6}{|l|}{ Milk } \\
\hline Yes & 67 & $65(97.1)$ & $2.141(1.911-3.711)$ & 8.247 & 0.046 \\
\hline No & 33 & $28(84.1)$ & & & \\
\hline \multicolumn{6}{|l|}{ Meat } \\
\hline Yes & 43 & $43(100.0)$ & $1.145(0.789-1.654)$ & 3.123 & 0.081 \\
\hline No & 57 & $50(87.7)$ & & & \\
\hline \multicolumn{6}{|l|}{ Corn meal } \\
\hline Yes & 79 & 74(93.4) & $0.654(1.112-1763)$ & 10.231 & 0.014 \\
\hline No & 21 & 19(90.5) & & & \\
\hline \multicolumn{6}{|l|}{ Date } \\
\hline Yes & 45 & $42(93.3)$ & $2.789(1.002-3.456)$ & 8.911 & 0.043 \\
\hline No & 55 & $51(92.7)$ & & & \\
\hline \multicolumn{6}{|c|}{ Brabisko /Biski (local food) } \\
\hline Yes & 36 & $11(30.6)$ & $1.156(0.711-1.811)$ & 11.654 & 0.048 \\
\hline No & 64 & $60(93.8)$ & & & \\
\hline \multicolumn{6}{|l|}{ Imported Rice } \\
\hline Yes & 22 & $17(77.3)$ & $1.010(1.151-1.863)$ & 7.521 & 0.063 \\
\hline No & 78 & $76(97.4)$ & & & \\
\hline \multicolumn{6}{|l|}{ Native Rice } \\
\hline Yes & 63 & $59(93.4)$ & $2.500(1.001-3.457)$ & 9.112 & 0.050 \\
\hline No & 37 & $34(91.9)$ & & & \\
\hline
\end{tabular}


Special Conference Edition, November, 2017

Table 4: Concentration of AFM1 in breast milk and urine samples of lactating mothers according to selected socio-demographic factors

\begin{tabular}{|c|c|c|c|c|}
\hline $\begin{array}{l}\text { Socio-demographic } \\
\text { factors /samples }\end{array}$ & $\begin{array}{l}\text { Sample tested } \\
\text { No. } \\
\mathrm{N}=100\end{array}$ & $\begin{array}{l}\text { Positive samples } \\
\text { No. }\end{array}$ & $\begin{array}{l}\text { Percentage of } \\
\text { positive }\end{array}$ & $\begin{array}{l}\text { Mean AFM1 } \\
(\mu \mathrm{g} / \mathrm{L})\end{array}$ \\
\hline \multicolumn{5}{|l|}{ Milk Sample } \\
\hline \multicolumn{5}{|c|}{ Occupational Position Of Mothers } \\
\hline Employed & 13 & 09 & 69.2 & $0.06( \pm 0.02)$ \\
\hline Unemployed & 87 & 73 & 83.9 & $0.07( \pm 0.01)$ \\
\hline \multicolumn{5}{|l|}{ Age } \\
\hline $18-25$ & 55 & 46 & 83.6 & $0.07( \pm 0.03)$ \\
\hline $26-33$ & 39 & 32 & 82.1 & $0.05( \pm 0.02)$ \\
\hline $34-41$ & 05 & 03 & 60.0 & $0.07( \pm 0.01)$ \\
\hline 42-above & 01 & 01 & 100.0 & $0.04( \pm 0.03)$ \\
\hline \multicolumn{5}{|l|}{ Educational Level } \\
\hline Informal education & 39 & 38 & 97.4 & $0.07( \pm 0.02)$ \\
\hline Islamic education & 43 & 30 & 69.8 & $0.06( \pm 0.01)$ \\
\hline Primary school cert. & 12 & 09 & 75.0 & $0.07( \pm 0.03)$ \\
\hline Secondary School & 06 & 05 & 83.3 & $0.06( \pm 0.02)$ \\
\hline \multirow{2}{*}{\multicolumn{5}{|c|}{$\begin{array}{l}\text { Urine Sample } \\
\text { Occupational Position of Mothers }\end{array}$}} \\
\hline & & & & \\
\hline Employed & 13 & 6 & 46.1 & $0.04( \pm 0.01)$ \\
\hline Unemployed & 87 & 87 & 100.0 & $0.05( \pm 0.02)$ \\
\hline \multicolumn{5}{|l|}{ Age } \\
\hline $18-25$ & 55 & 51 & 92.7 & $0.05( \pm 0.02)$ \\
\hline $26-33$ & 39 & 36 & 92.3 & $0.04( \pm 0.02)$ \\
\hline $34-41$ & 05 & 05 & 100.0 & $0.05( \pm 0.02)$ \\
\hline 42-above & 01 & 01 & 100.0 & $0.04( \pm 0.01)$ \\
\hline \multicolumn{5}{|l|}{ Education Level } \\
\hline Informal education & 39 & 39 & 97.4 & $0.05( \pm 0.02)$ \\
\hline Islamic education & 43 & 37 & 86.0 & $0.04( \pm 0.02)$ \\
\hline Primary school cert. & 12 & 12 & 100.0 & $0.04( \pm 0.01)$ \\
\hline $\begin{array}{l}\text { Secondary school } \\
\text { cert. }\end{array}$ & 06 & 05 & 83.3 & $0.04( \pm 0.02)$ \\
\hline
\end{tabular}

\section{DISCUSSION}

The occurrence of AFM1 among lactating mothers breast milk samples is at $82 \%$ frequency, while $93 \%$ of urine samples contained AFM1. This could be as a result of dietary exposure of the screened mothers to AFMB1 which is metabolized to AFM1 and secreted in the breast milk and also excreted in the urine. Considerably, another independent screening by Adejumo, et al (2013) who also reported occurrence of AFM1in $82 \%$ of breast milk samples in Ogun state, Nigeria. Abdulrazzaq et al.(2003) and Sadeghi et al. (2009) in United Arab Emirate and Iran respectively reported $99.5 \%$ and $98.1 \%$ frequencies. The percentage occurrence in this study is higher than that reported in of Sierra Leone, Cameroun and Egypt, 31\%, 4.8\%, and $56 \%$ respectively (Jonsyn et al, 1995; Tchana et al., 2010; Polychronaki et al., 2007). This could be as a result of differences in the type of food consumed, storage condition of foods and lifestyle of the people as well as level of contamination with the secreting Aspergillus species. Urinary excretion of AFM1 among lactating mothers showed that $100 \%$ of unemployed mothers had tested for the toxin in their urine compared to the employed mothers. This suggests that the unemployed mothers are better exposed through their diets. One hundred percent of people with informal education and primary school leavers were exposed to AFM1; the educational qualification of lactating mothers is significantly associated with secretion of AFM1 in breast milk, the highest \% secretions was people with informal education. This disagrees with Adejomo et al. (2013), that reported that the primary school leavers had the highest level of AFM1 in there breast milk samples. The exposure based on excretion of AFM1 in urine disagrees with Mason et al, (2015). that recorded that BSc had highest exposure of AFM1. Concentration of AFM1 among lactating mothers' breast milk in relation to socio-demographic factors expressed the highest concentration among unemployed and age bracket $18-25$ and $34-41$ with $0.07 \mu \mathrm{g} / \mathrm{l}$ which could be that the employed mothers 
were more careful with quality of food they consumed while the unemployed mothers may concentrate on the quantity of food they took. In the case of excretion in urine $0.05 \mu \mathrm{g} / \mathrm{l}$ AFM1 was tested among unemployed mothers with lower concentration among the age of 42 and above having $0.04 \mu \mathrm{g} / \mathrm{l}$ this may be due to the elder mothers may be more careful on quality of food consumed. Looking at educational background within $72 \mathrm{hrs}$ those with informal education had highest concentration of $0.05 \mu \mathrm{g} / \mathrm{l}$ under this category they tend to be more likely less careful. This was within the limits gotten by Adejumo et al (2013) but lower in Oluwafemi (2012),

\section{CONCLUSION}

The level of AFM1 was assessed in the breast milk secretions and excretions of lactating mothers breast milk whose infants were on

\section{REFERENCES}

Abdulrazzaq, Y.M.,Osman, N.,Yousif, Z.M., AlFalahi, S.(2003). Aflatoxin M1 in Breast Milk of UAE women. Ann.Trop. paediat., 23:173-179.

Adejumo, O., Atanda. O.,Raiola, A., Somorin, Y., Bandyopadhyay, R. and Ritieni, A., (2013) . Correlation between Aflatoxin M1 content of breast milk, dietary exposure to aflatoxin B1 and socioeconomic status of lactating mothers in Ogun State, Nigeria: Food and Chemical Toxicology, 56:171-177

Bennett, J. W. and Klich, M. (2003). Mycotoxins. Clin. Microbiol Rev., 16:497516.

Bhat, R., Rai, R.V. and Karim, A. A. (2010). Mycotoxins in food and feed: present status and future concerns. Comprehens Rev. Food Sci. Food Safety, 9:57-81.

Blout, W. P. (1961) Turkey "X" disease. Turkeys 9:52,55-58,61,77.

Jonsyn, F.E., Maxwell, S.M., Hendrickse, R.G., (1995). Ochratoxin A and aflatoxins in breast milk samples from Sierra Leone. Mycopathology 131, 121-126.

Ghiasian, S.A. and Maghsood, A.H. (2012). Infants' Exposure to Aflatoxin M1 from mother's Breast milk in Iran: IranianJ. Pub. Health, 41(3):119-126

Mason, S., Hajimohammadi, B., Ehrampoush, M.H., Khabiri, F., Soltani, M.(2015). A Survey on relationship between diet and urinary excretion of aflatoxin M1: a screening pilot study on Iranian population. Journal of Food Quality and Hazards Control, 2 : 66-70 admission in General Sani Abachia Specialist Hospital Damaturu and the occurrence was found to be considerably high. However the following conclusions were made:

The percentage occurrence of lactating mothers' breast milk and urine were $82 \%$ and 93\% respectively. While the mean concentration of AFM 1 in breast milk and urine samples were found to be $0.057 \mu \mathrm{g} / \mathrm{L}$ and $0.069 \mu / L$ respectively.

It should be noted that, the concentration of AFM1 in all the breast milk samples used were higher than the acceptable tolerance level of $0.05 \mu \mathrm{g} / \mathrm{l}$ for infants milk by the Codex Alimentarius. This posses a concern that infants that were on admission in the selected facility where exposed to AFM1.This implies that AFM1 has the potential to be a public health problem in Damaturu.

Masri, M.S., Booth, A.N. and Hsieh, D.P. (1974). Comparative metabolic conversion of aflatoxin $\mathrm{B} 1$ to $\mathrm{M} 1$ and $\mathrm{Q} 1$ by monkey, rat and chicken liver. LifeSci., 15:203-212.

Oluwafemi, F.T .(2012). Aflatoxin M1 levels in lactating mothers in two Nigerian cities.Archives of Clinical Microbiology, 3(4).

Post Offices- with map of LGA (2012) NIPOST.Archived from the original, Ret.2009-10-20.)

Polychronaki, N., West, R.M., Turner, P.C., Amra, H., Abdel-Wahhab, M., Mykkanen, H., El-Nezami, H.,( 2007). A longitudinal assessment of aflatoxinM1 excretion in breast milk of selected Egyptian mothers. Fd. Chem. Toxicol. 45:1210-1215.

Richard J.L. (2008). Discovery of Aflatoxins and Significant Historical Features.Toxin Review, 27:3-4

Sadeghi, N., Oveisi, M.R., Jannat, B., Hajimahmoodi, M., Bonyani, H., Jannat, F., ( ( 2009) Incidence of Aflatoxin M1 in human breast milk in Tehran, Iran. Food Contro20: 75-78.

Tchana, A.N., Moundipa, P.F., Tchouanguep, F.M., 2010. Aflatoxin contamination in food and body fluids in relation to malnutrition and cancer status in Cameroon. Int. J. Environ. Res. Pub. Health 7: 178-188.

Tomerak, R.H., Shaban, H.H., Khalafallah, O.A. and El Shazly, M.N. (2011). Assessment of exposure of Egyptian infants to aflatoxin M1 through breast milk; J Egypt Public Health Assoc.,86:51-55; 0013-2446. 